\title{
Differences between feelings, emotions and desires in terms of interactive quality
}

\author{
Lawrence J. Cookson \\ School of Biological Sciences \\ Monash University, Clayton, Vic. 3800, Australia.
}

\begin{abstract}
The importance of interactive quality has become central to understanding the meaning of wildness, the natural state. This article examines the differences between feelings, emotions and desires according to their roles during interaction. Emotions and desires are placed on the engaging side of the interactive loop, while feelings register the feedback gained from interaction. Feelings are further divided into somatic and neocortical feelings, where somatic feelings such pain and hunger register how the body is being affected, while neocortical feelings are based upon the pleasure or displeasure for how a constructed sense of fairness and personal context was affected. Desires are thought to arise directly from bodily organs and from a theorised neocortical 'interaction desire' that seeks parsimony within the organisation of its developing pathways. The production of emotions is influenced by the level of wildness or ease of interaction being experienced within a given environment, so that they become more prevalent, varied and extreme during conditions of difficulty and conflict.
\end{abstract}

Keywords: Interaction, desire, emotion, feeling, parsimony, wildness, surprise

\section{INTRODUCTION}

Interaction is a fundamental requirement for any animal (1-3), where it receives stimulation from the various constituents of its niche (positive or negative), processes that information internally, and then provides a response. The quality of interaction can vary, and it was suggested that highest quality leads to a state of wildness where behaviour becomes more fluent, natural and targeted (4). The more appropriate and timely the response, the more chance an animal has of surviving. For example, animals with increasing levels of wildness are known to have greater chances of survival in nature compared to human-reared animals, due to their improved knowledge of how to interact $(5,6)$.

\section{INTERACTIVE LOOP}

Emotions, desires and feelings are significant components in the interactive process, and presumably evolved during wildness, the natural state prevalent before human civilisation. Currently, these motivational states can be difficult to distinguish, often being grouped together or seen as aspects of each other. For example, desires $(7,8)$ and feelings are often included with emotions $(9,10)$, as may be pain (11) surprise and interest (12). However, by focusing on their roles during interaction it may be possible to gain improved distinction. These motivational states appear to be readily divisible based upon the two halves of the interactive process, where an organism can engage to have an interaction and then obtain feedback as lesson on interactive outcome.

Emotions and desire could be placed on the engaging side of the interactive loop. Emotions are motivated or action readiness stances $(13,14)$. They are also intimately involved with cognition or the construction of plans, and in our species appear to be mental constructs that are 
formulated within the neocortex $(15,16)$. Emotions may not be separable from cognition $(17)$, and they appear to prepare the body and mind for action.

Feelings appear to cater for the feedback side of interactions, and their coordination resides in the limbic system rather than being entwined with cognition and planning in the neocortex. For example, pleasure and displeasure involve the hypothalamus (18) and ventral striatum (19). Pain is experienced at least partially in the cingulate cortex (20). The amygdala is involved with surprise, fear and anxiety (21-24). The feedback received by the limbic system can also trigger automatic behaviours such as expressions, attack behaviour, drinking, feeding and copulatory actions $(18,25)$. Feelings are responses to significant events and often motivate further actions and emotions (9).

The timing between feedback and engagement can be almost instantaneous, so that each state appears tied to the other. Emotions are often partly defined by their feeling states. However, it may be possible to disentangle emotions from feelings so that their roles during interaction are clearer. Plutchik (9) also recognised the role of a chain of events or feedback loops in the construction of emotions. Emotions and desires could be used when an animal attempts interaction. After the interaction, feedback may be registered as feelings. The following discussion shows how they could be separated according to these roles.

\section{Somatic feelings}

\section{FEELINGS}

For the most simple of interactions, there would seem to be three possible feedback outcomes imposed by external forces. These outcomes from interaction may register in the limbic system as 'somatic feelings' in any animal, irrespective of whether they have a neocortex that is capable of cognition and its emotions. The results of an interaction may be positive (satisfying), negative (painful or unresponsive) or a surprise (unknown, yet to be categorised) although the latter option will usually soon sort into either of the first two options upon further investigation and exposure. The possible neutral non-reaction should still register as negative or disappointing, because the engaging attempt seeks positive outcome rather than disinterest. These kinds of somatic feelings provide a sense of one's physical self (26).

The body has a number of needs represented by states such as hunger, thirst, sexual desire and thermal homeostasis. The fulfilment during interaction of these somatic desires produces somatic feelings of satisfaction such as the taste of food, filled stomach, prevention of nausea, orgasm and thermal comfort. These desires are important, so when they cannot be filled they can become matters of survival leading to starvation, gasping for air and shivering for example. Some reflexes can help to relieve these feelings; however, continued failure to fulfil the underlying desires can have significant implications and may soon escalate into urgencies. The word urgency is used here rather than displeasure, as the latter implies some cognitive judgement that hinges upon a preferred order or level of fairness. For comparison with the 'neocortical feelings' described later, it is noteworthy that these somatic feelings of satisfaction and urgencies cannot be replicated by thought but require physical involvement. Hunger can be ignored or remembered but not fulfilled by thought. Somatic feelings cannot be altered in kind by cognition.

Pain provides another example of the difference between feeling and emotion. We can feel pain but cannot repeat that sensation cognitively or emotionally. We can remember that pain hurts, that it is upsetting, fear it, but we cannot actually produce the pain sensation other than by 
hurting the body again. The feeling of pain, and the cognition or anticipation of pain, produces different neural activation patterns (20). The phantom pain experienced by amputees may seem to contradict this rule. However, such pain is thought to be due to peripheral neuromas, spinal cord irregularities, and limbic input systems that stimulate the neocortex to recognise pain, rather than the neocortex initiating the feeling itself. A number of theorists also consider that pain is not an emotion $(18,27)$.

Surprise is another example of a feeling that cannot reproduce itself as an emotion, and then repeat the same feeling. We cannot think or emotionally act to produce the feeling of surprise, because we already know the result. Similarly, we cannot tickle ourselves because there is no surprise in the action (28). The feeling of surprise usually dissipates very quickly as it cannot produce a direct emotion of its own to create a self-sustaining feedback loop, and the animal does not send an attempt into the neocortex aimed at confounding itself again. The limbic reflexive expression or reaction to surprise might be to jump, eye-blink, or have a rush of blood to the muscles in readiness for physical action and orientation $(29,30)$. These actions however are not emotions but expressions, reflexes and physiological responses triggered by a somatic feeling. Instead, the emotional neocortical response to surprise is to assess and understand quickly. In a split second it might be realised that the surprise is not dangerous (a practical joke perhaps), and the pent up energy can be released with a laugh. Or surprise might lead to curiosity. If the surprise is dangerous then the emotions generated may be anger or fear. Others have considered that surprise (startle) may not be an emotion $(12,13)$.

In certain instances of surprise the limbic system can even bypass the neocortex and its cognition and emotions. If the surprise is very dangerous or repugnant, the animal may go into shock which again is a feeling rather than emotion. It may not be possible to escape the cause of surprise such as a predator. Such a sudden surprise means that the neocortex was outwitted so still may not hold any answers. Shock produces a cognitive feeling of helplessness. It is a limbic assessment or feeling rather than an emotion that can act. After the reaction, we might say 'I am shocked', but that is a cognitive explanation rather than the production of more shock. During shock the limbic system bypasses the neocortex for a while, and reflexive reactions mediated by its sympathetic nervous system take over. There may be fight, flight or freeze reactions. The neocortex may be so little used that the mind will seem numb or dazed $(31,32)$, and as no desire or emotion travels through the interactive loop no neocortical feeling will be experienced and pain may not be interpreted. If still alive, the neocortex may gradually formulate a plan and regain behavioural control.

Disgust is another form of surprise for the unknown or unexpected that illustrates the two groups of feelings presented here. Firstly, visceral or gustatory disgust can be a reflexive feeling or direct bodily reaction to taste, such as bitterness $(33,34)$. This form of disgust will not produce an emotion directly that can replicate such a feeling of disgust, but will lead to emotions that can remember and avoid repeated consumption of the disgusting food. Such a disgust feeling may produce a reflexive action such as screwing up the face and a gaping mouth that tries to push out food (35). Alternatively, moral disgust can be felt as an offense to our cognitive sensibilities, culture or rules $(34,36)$, and many of its expressions may have originated from gustatory disgust $(37,38)$. This form of neocortical disgust can produce a matched emotion, as the more we think about the offense the more disgusted we can become.

\section{Neocortical feelings}

The somatic feelings for bodily satisfaction/urgency, pain and surprise cannot be replicated by emotion or neocortical activity. In contrast, there are a range of feelings that can trigger 
emotions that can then trigger the same feelings again, often instantaneously. We can feel anger, and emotionally think about the situation further and become even angrier $(39,40)$. Or emotionally think lovingly about a person and feel even more love. These neocortical feelings use cognition to contextualise their cause instantly so that they might deploy conforming emotions that carry the feeling into their next interaction or thoughts, which can replicate the same feeling again. Such feeling states then help to define the emotion. Alternatively, neocortical interpretation may suggest a different engagement path for the next interactive attempt. For example, rather than using anger we could choose reason or understanding instead, which might trigger a different set of contextualised feelings such as compassion and forgiveness (41). We can change the way we feel by changing the way we think (42). Intervention by the neocortex within the interactive loop provides opportunity for emotion regulation and modification $(14,43)$.

There may be only two main feeling states behind neocortical feelings and emotions, pleasant and unpleasant (44). Registration of this pleasant or unpleasant feeling appears to be inherited, common to all people and mammals, and central to the development of emotions $(45,46)$.

While we can contextualise and therefore feel a large variety of emotions, the actual underlying feeling state appears to reduce to various degrees of pleasure or displeasure. The level of arousal or intensity within this binary choice can vary from approval and happiness to ecstasy (pleasures) or disapproval and sadness to emptiness and misery (displeasures). However, the process of differentiating new feelings (such as anger, hate, love) from the original stock of pleasure and displeasure takes time to learn. For example, knowledge of context is vital before the displeasured feeling can be further conceptualised into fear rather than anger (47). This underlying differentiation of feelings into an original core of pleasure or displeasure has been used to explain emotional granularity $(45,48,49)$, where some people only know happy or sad while others can describe many feeling types in detail. The latter group would have learnt greater diversity in context, association and interpretation. For some, fear and anger simply produce an empty feeling.

The requirement for learning context to produce the full range of neocortical feelings and their emotions takes time. While many adults have a full range of emotions, they are not present ready-made from birth $(50,51)$, and require the involvement and experience of cognition (52). It would be interesting to understand the aim of the neocortex before emotions are needed. The involvement of cognition suggests that emotions are learnt, but what source is being modified?

While emotions are learnt, why they should care is not apparent. If emotions are inherited rather than learnt, then this question disappears as their reason for existing becomes one of survival and evolution, as elaborated by supporters of 'basic emotions' (53-58). However, in the constructionist approach for emotions favoured here, there could still be one inherited stem from which emotions arise. One original and inherited interactive loop is suggested by the inherited registration of pleasure or displeasure in the limbic system. However, this differentiation occurs on the feeling side of the interactive loop. The inherited component on the engaging side that may underpin learnt emotions is missing. Nevertheless, such a possibility for an 'original inherited interactive loop' may fit expectations. Gross and Barrett (43) consider that all mental states including emotion, cognition and perception arise from the one process, as they all involve subjective experience, expressive behaviour and physiological 
responses. There may be an 'interaction desire' that encapsulates an inherited motivation entering the neocortex.

\section{DESIRES}

While emotions are learnt and constructed (43), the desires that influence our emotions occur more deeply and can usually be assigned directly to certain survival needs and specific organs.

\section{Somatic desires}

Within the body each organ and tissue evolved to perform a specific function essential to survival. Tissues and organs needing a behavioural response send messages and hormones to the central nervous system to convey information about their condition and what they need if they are to perform $(59,60)$. Some needs are filled by involuntary or reflexive responses such as the heart beat, adjustment of the iris to differing light intensities, or churning the stomach to mix food.

In comparison, those needs that ask for significant behavioural response send their messages to the limbic system, especially the hypothalamus (18), where they are converted into desires that can then be sent into the neocortex for consideration $(25,61-63)$. There are different messages being sent from all parts of the body, the intensity of which varies as some cells become hungry and others satiated. The stomach and blood sugar levels alert their condition to the limbic system which creates a desire for food (64). Hydration levels in the blood are noted by the median preoptic nucleus in the hypothalamus which produces thirst (65). If we become short of air, the lungs and brain will send the cortex an increased desire to breathe or gasp. The gonads secrete hormones that develop the desire for sex. The bowels and bladder desire excretion when full. The inner ear desires steadiness and balance in head posture (66).

Desires could be distinguished from emotions as inherited motivations that arise from specific bodily organs and have direct survival and biological purpose. They can be called desires because they are like wishes or requests placed before the neocortex for it to consider during its further interactive attempts. Nevertheless, desire could build to become an urgent and pressing need. Alternatively, the neocortex may require the somatic desire to remain patient or hidden, demonstrating its higher level control. The emergence of higher brain functions has inhibited the affectively conscious states of lower brain functions (19). For example, attempts to consciously inhibit sexual arousal activated the right superior frontal gyrus rather than limbic structures (67). This expanded capacity is especially important for those animals living in complex environments where correct interaction is not always straight forward. Even so, being a learning organ, the neocortex must gain experience before it can develop these options.

While some consider that drives such as hunger and sex should be included with emotions because they possess affects and other emotional facets (58), desire is not included in most sets of basic emotions suggesting that most theorists do not believe them to be emotions (12). Ortony and Turner (12) consider desires to be motivational states that differ from emotional states as they simply want rather than anticipate pleasure, with the latter implying some cognitive involvement and approval.

\section{Interaction desire}

Somatic desires are like wishes placed before the neocortex for it to consider during its next interactive attempt. They do not enter the neocortex on their own as a flood of conflicting desires making a confusion of demands. Ultimately, there should be one other desire that leads the neocortex and oversees all other desires making requests so that it can sort them according 
to its greater understanding for the reality of its environment. There are many signs that an 'interaction desire' has control or at least pause over the other desires, especially as that desire matures and gains more interactive experience in the neocortex with which to compare. We can suppress the desire for food and control when we eat. Some might even hunger strike to the point of death by starvation, if they think the cause was just (68). The desire to excrete can be suppressed, for a while at least, by an appreciation for social interaction. The desire to interact in the right way can also mediate our desire for sex. A proportion of priests have lifelong control over their sexual desire, if they think it right. An interaction desire seems able to control or temper the other desires if needed and may also underpin emotions, similar to the way pleasure and displeasure underpins neocortical feelings.

Previously, a parsimony desire for the neocortex was hypothesised that has concern for simplifying the ordering of things within the mind (69), and could double as an interaction desire. The parsimony desire was used to explain our species' interest in the esoteric pleasures such as music, art, poetry. It also explained why improvements in parsimony could be experienced as the pleasure of insight, eureka moments, achievement and understanding. A mechanism by which it might operate was suggested, where the more subcortical pleasure hotspots or nuclei that can be stimulated as feedback in the limbic system at once after an interaction, then the more parsimonious and skilful must be the arrangements for pathways within the neocortex (69). This parsimony desire might also impinge on the more life-survival states felt during emotion. Improvement in interactive quality through internal improvements in parsimony of mind is a key factor in producing the wild state $(70,71)$. The term interaction desire rather than parsimony desire is used in this article as the main purpose of the desire is to achieve good interaction, rather than some obscure notion of parsimony, even though the best way to measure interactive quality is by the measurement of parsimony as previously described (69).

The neocortex could focus on interactive quality rather than survival per se as proper interaction and associated improvements in wildness should improve survival chances in any case $(71,69)$. If survival were the prime focus of the neocortex, then it is understandable that its contents might become inherited and hardwired as record of the hard lessons instilled by evolution. However, if the prime focus of the neocortex is quality of interaction, then it should be plastic and malleable, more sensual and alert to the realities of the environment into which it is born. This contrasting view on the role of the neocortex explains the oddity in evolutionary terms of suicide, so prevalent in our species $(72,73)$. The priority in our species is interactive quality, that is, whether prospects for positive and fulfilling interaction seem real and achievable. Mere survival is not enough.

The interaction desire will need to deal with not just the pathways of understanding developing in its neocortex, but a range of inputs including the somatic feelings experienced through surprise, urgency/satisfaction and pain. The loss of someone can feel bad enough, but if coupled with a sense of injustice as well then consequential actions can soon escalate into the dramatic.

A neocortex ruled by a desire for interactive quality will produce minds that want to do the right thing simply because that state will represent the most parsimonious arrangement available. It would be a sign that more things can be interacted with directly, indicating attunement and interactive skill. The expectation for positive interaction is our first assumption. Children especially, try to be 'good'. They begin to develop an inequality aversion 
between the ages of 3 and 8 (74). People seem to be born with an innate moral compass (7577), where everyone aims to do the right thing, or at least starts out that way. A sense of fairness is common in humans and primates (78-80). Every emotion hides a concern, a disposition to prefer particular states of the world $(13,81)$. This interpretation of how the world should be or of how we should be treated shows the underlying cognitive influence of an interaction desire. It shows that we develop certain expectations, morals, standards, bonds, likes, and become emotional when they are not met.

\section{EMOTIONS}

An assumption in wildness, the natural state, is that interactive quality within a wild niche is high allowing an animal to do, or try to do, whatever it wants. It can feel a desire and pursue it directly and honestly. The interaction desire is suggested as a positive and engaging desire that evolved to assume that it would monitor and help shape the neocortex within a specialised niche where attunement is possible. If the interaction desire can meet its needs for efficient and comfortable outcome, then it will feel pleasure and it has no need to change. The interaction desire can continue to enter the neocortex on its own or while chaperoning other desires, unabated. It can be wild and free. However, such a continuously blissful state based on the pursuit of simple desires rarely lasts, especially for animals living in complex environments. Such pure interactive desire is often blocked or unfulfilled with feedback that is painful, unpleasurable or unresponsive. The interactive attempt was blocked in some way. At this point, many wild animals may not survive beyond their first block. They may be eaten, yet, they die wild. Their psyche is not dented.

Upon block, the unpleasant feeling experienced is registered in the neocortex, becomes associated with the context of the interaction, and the neocortex couples the context and unpleasant feeling into an appraisal of the block, whether it is dangerous, lazy or uninterested for example. The results of previous experiences and interactions become represented in the neocortex as somatic markers or representations of feeling (blocks) that then influence further decisions and emotions $(26,58,82,83)$. The prefrontal cortex is involved in constructing reappraisal strategies that influence the production of emotions (42). The experience of pain for example, a feeling well studied, involves processes leading from the limbic system to the neocortex where it contributes to the emotional aspects (rather than the feeling) of pain (84), its representation and interpretation (85).

After the experience of block, those animals that do survive should not send their next burst of desiring interactive effort into the neocortex in the same way or with the same naivety. With knowledge about the nature of the block modelled in the neocortex, desire could anticipate the effects of the block early, before the next interaction. The interaction desire would need to cope or adjust to the block somehow, which it may do by converting itself into an emotion. Frustration or the presence of a barrier blocking the goal path provides examples of situations that elicit multiple emotions (54). Appraisal (of the block), and cognitive activity, are involved in the production of emotions $(81,82,86,87)$. An emotional response includes the fundamental feeling aroused by the sensory stimuli, followed in the cortex by the congnizance of the stimulating situation, and emotions themselves are conditioned responses subsequently formed $(47,88,89)$.

The type of emotion that the interaction desire converts into will hinge on an appraisal of the kind of block experienced (indifference, danger, anger from other parties, pain), past experience or neocortical understanding of the environment or its chances, the intensity of other requesting somatic desires, an assessment of the threat posed by the block, and the 
internal state of confidence, health or well-being. Emotions have been recognised as being constructed (90), and the steps described could allow a rich diversity to arise.

Emotions may try to tackle the block by removing it (anger), appealing to the broader niche for help (hope), appealing directly to another who is capable (love), deceiving the block (lying or cheating), or by fleeing (fear). It is easy to see how negative emotions might be stirred by block especially when one is clearly identified and disturbing. For positive emotions such as love, the block is often felt as social rejection (91), or as a generally unfulfilled state without any clear cause or disturbing focus against which to act. 'A person is ready to fall in love because of one of a number of reasons, loneliness, sexual need, dissatisfaction, or a need of variety' (13). The response to social exclusion can vary from prosocial ones aimed at becoming more likeable, to antisocial responses including avoidance and aggression (92).

Emotions ready the body for action, and are energy intensive and agitated states whose purpose is to resolve issues or engage positively so that life can be easier and happier. 'The function of emotion is to restore the individual to a state of equilibrium' (9). Once the 'no more action needed' signal has sounded there is no more need for emotion (13). The excessive use of some emotions such as anger has been linked to adverse health outcomes (93). In the natural state where interactive quality is high, there should be fewer blocks encountered allowing the more direct pursuit of basic desires and sociality. However, in our modern society with so many complications, conflicts and stress, greater variety and more extreme emotions are experienced. An example of this difference is that indigenous cultures generally have fewer emotion words than in western civilisation (94-96).

\section{CONCLUSION}

It is proposed that desires, emotions and feelings can be divided according to their roles during interaction. Desires and emotions engage with interaction, while feelings provide feedback. The somatic feelings reveal how interactive outcomes affect the body, while neocortical feelings of pleasure (approval) or displeasure reveal how the feedback squares with a developing cognition and understanding. On the engaging side of interaction, desires arise firstly and directly from bodily organs to produce somatic desires (such as hunger and thirst) and from a theorised neocortical 'interaction desire' that prefers parsimony and ease of interaction within the developing organisation of its neocortical pathways. When those pathways are blocked or become unfulfilling, emotions may be deployed in an active attempt to resolve the problem. During the natural state of wildness, it is further postulated that the organism can live more naturally using a desire and feeling psychology, 'pleasure and pain'. The deployment of emotions becomes more prevalent and extreme during conflict and difficulty. Nevertheless, fundamentally, they are designed to return the organism to a state of homeostasis and natural ease.

\section{References}

1. Abrams, P.A. (1987). On classifying interactions between populations. Oecologia, 73, 272-281.

2. Hommel, B. (1993). The relationship between stimulus processing and response selection in the Simon task: Evidence for a temporal overlap. Psychological Research, 55, 280-290.

3. Wootton, J.T., \& Emmerson, M. (2005). Measurement of interaction strength in nature. Annual Review of Ecology, Evolution, and Systematics, 36, 419-444.

4. Cookson, L.J. (2011). A definition for wildness. Ecopsychology, 3, 187-193.

5. Stoinski, T.S., Beck, B.B., Bloomsmith, M.A. \& Maple, T.L. (2003). A behavioural comparison of captiveborn, reintroduced golden lion tamarins and their wild-born offspring. Behaviour, 140, 137-160. 
6. Roche, E.A., Cuthbert, F.J. \& Arnold, T.W. (2008). Relative fitness of wild and captive-reared piping plovers: Does egg salvage contribute to recovery of the endangered Great Lakes population? Biological Conservation, 141, 3079-3088.

7. Arnold, M.B. (1960). Emotion and Personality. New York: Columbia University Press.

8. Frijda, N.H. (1986). The Emotions. New York: Cambridge University Press.

9. Plutchik, R. (2001). The nature of emotions. American Scientist, 89, 344-350.

10. Lang, P.J. (2010). Emotion and motivation: Toward consensus definitions and a common research purpose. Emotion Review, 2, 229-233.

11. Mowrer, O.H. (1960). Learning Theory and Behavior. New York: Wiley.

12. Ortony, A., \& Turner, T.J. (1990). What's basic about basic emotions? Psychological Review, 97, 315-331.

13. Frijda, N.H. (1988). The laws of emotion. American Psychologist, 43, 349-358.

14. Cole, P.M., Martin, S.E., \& Dennis, T.A. (2004). Emotion regulation as a scientific construct: Methodological challenges and directions for child development research. Child Development, 75, 317-333.

15. Damasio, A.R., Grabowski, T.J., Bechara, A., Damasio, H., Ponto, L.L.B., Parvizi, J., \& Hichwa, R.D. (2000). Subcortical and cortical brain activity during the feeling of self-generated emotions. Nature Neuroscience, 3, 1049-1056.

16. Phelps, E.A. (2006). Emotion and cognition: Insights from studies of the human amygdala. Annual Review of Psychology, 57, 27-53.

17. Smaldino, P.E., \& Schank, J.C. (2012). Invariants of human emotion. Behavioral and Brain Sciences, 35, 164.

18. Joseph, R. (1992). The limbic system: Emotion, laterality, and unconscious mind. Psychoanalytic Review, 79, 405-456.

19. Burgdorf, J., \& Panksepp, J. (2006). The neurobiology of positive emotions. Neuroscience and Biobehavioral Reviews, 30, 173-187.

20. Ploghaus, A., Tracey, I., Gati, J.S., Clare, S., Menon, R.S., Matthews, P.M., \& Rawlins, J.N.P. (1999). Dissociating pain from its anticipation in the human brain. Science, 284, 1979-1981.

21. Davis, M. (1992). The role of the amygdala in fear and anxiety. Annual Review of Neuroscience, 15, 353375.

22. LeDoux, J.E. (2000). Emotion circuits in the brain. Annual Review of Neuroscience, 23, 155-184.

23. Calder, A.J., Lawrence, A.D., \& Young, A.W. (2001). Neuropsychology of fear and loathing. Nature Reviews Neuroscience, 2, 352-363.

24. Kim, H., Somerville, L.J., Johnstone, T., Alexander, A., \& Whalen, P.J. (2003). Inverse amygdala and medial prefrontal cortex responses to surprised faces. NeuroReport, 14, 2317-2322.

25. Mogenson, G.J., Jones, D.L., \& Yim, C.Y. (1980). From motivation to action: Functional interface between the limbic system and the motor system. Progress in Neurobiology, 14, 69-97.

26. Craig, A.D. (2002). How do you feel? Interoception: the sense of the physiological condition of the body. Nature Reviews Neuroscience, 3, 655-666.

27. Williams, A.C.C (2002). Facial expression of pain: An evolutionary account. Behavioral and Brain Sciences, 25, 439-388.

28. Van Doorn, G., Hohwy, J., \& Symmons, M. (2014). Can you tickle yourself if you swap bodies with someone else? Consciousness and Cognition, 23, 1-11.

29. Lang, P.J. (1995). The emotion probe. Studies of motivation and attention. American Psychologist, 50, 372-385.

30. Drummond, P.D., \& Lim, H.K. (2000). The significance of blushing for fair- and dark-skinned people. Personality and Individual Differences, 29, 1123-1132.

31. Bryant, R.A., Friedman, M.J., Spiegel, D., Ursano, R., \& Strain, J. (2010). A review of acute stress disorder in DSM-5. Depression and Anxiety, 28, 802-817. 
32. Testa, A., Giannuzzi, R., Sollazzo, F., Petrongolo, L., Bernardini, L., \& Daini, S. (2013). Psychiatric emergencies (part 1): psychiatric disorders causing organic symptoms. European Review for Medical and Pharmacological Sciences, 17 (Suppl 1), 55-64.

33. Haidt, J., McCauley, C., \& Rozin, P. (1994). Individual differences in sensitivity to disgust: A scale sampling seven domains of disgust elicitors. Personality and Individual Differences, 16, 701-713.

34. Danovitch, J., \& Bloom, P. (2009). Children's extension of disgust to physical and moral events. Emotion, 9, 107-112.

35. Rosenstein, D., \& Oster, H. (1988). Differential facial responses to four basic tastes in newborns. Child Development, 59, 1555-1568.

36. Eskine, K.J., Kacinik, N.A., \& Prinz, J.J. (2011). A bad taste in the mouth: Gustatory disgust influences moral judgment. Psychological Sciences, 22, 295-299.

37. Rozin, P., \& Fallon, A.E. (1987). A perspective on disgust. Psychological Review, 94, 23-41.

38. Stevenson, R.J., Oaten, M.J., Case, T.I., Repacholi, B.M., \& Wagland, P. (2010). Children's response to adult disgust elicitors: Development and Acquisition. Developmental Psychology, 46, 165-177.

39. Kross, E., Ayduk, O., \& Mischel, W. (2005). When asking "why" does not hurt. Distinguishing rumination from reflective processing of negative emotions. Psychological Science, 16, 709-715.

40. Denson, T.F., Moulds, M.L., \& Grisham, J.R. (2012). The effects of analytical rumination, reappraisal, and distraction on anger experience. Behavior Therapy, 43, 355-364.

41. Berry, J.W., Worthington, E.L., O’Connor, L.E., Parrott, L., \& Wade, N.G. (2005). Forgivingness, vengeful rumination, and affective traits. Journal of Personality, 73, 183-226.

42. Ochsner, K.N., Bunge, S.A., Gross, J.J., \& Gabrieli, J.D.E. (2002). Rethinking feelings: An fMRI study of the cognitive regulation of emotion. Journal of Cognitive Neuroscience, 14, 1215-1229.

43. Gross, J.J., \& Barrett, L.F. (2011). Emotion generation and emotion regulation: One or two depends on your point of view. Emotion Review, 3, 8-16.

44. Lindquist, K.A., Wager, T.D., Kober, H., Bliss-Moreau, E., \& Barrett, L.F. (2012). The brain basis of emotion: A meta-analytic review. Behavioral and Brain Sciences, 35, 121-202.

45. Barrett, L.F. (2006). Solving the emotion paradox: Categorization and the experience of emotion. Personality and Social Psychology Review, 10, 20-46.

46. Barrett, L.F., Mesquita, B., Ochsner, K.N., \& Gross, J.J. (2007). The experience of emotion. Annual Review of Psychology, 58, 373-403.

47. Clore, G.L., \& Ortony, A. (2013). Psychological construction in the OCC model of emotion. Emotion Review, 5, 335-343.

48. Barrett, L.F. (1998). Discrete emotions or dimensions? The role of valence focus and arousal focus. Cognition and Emotion, 12, 579-599.

49. Barrett, L.F. (2004). Feeling or words? Understanding the content in self-report ratings of experienced emotion. Journal of Personality and Social Psychology, 87, 266-281.

50. Spitz, R.A. (1949). The role of ecological factors in emotional development in infancy. Child Development, 20, 145-155.

51. Widen, S.C., \& Russell, J.A. (2003). A closer look at preschoolers' freely produced labels for facial expressions. Developmental Psychology, 39, 114-128.

52. Davidson, R.J., \& Irwin, W. (1999). The functional neuroanatomy of emotion and affective style. Trends in Cognitive Sciences, 3, 11-21.

53. Izard, C.E. (1992). Basic emotions, relations among emotions, and emotion-cognition relations. Psychological Review, 99, 561-565.

54. Izard, C.E., Ackerman, B.P., Schoff, K.M., \& Fine, S.E. (2000). Self-organization of discrete emotions, emotion patterns, and emotion-cognition relations. In M.D. Lewis \& I. Granic (Eds.), Emotion, Development, and Self-Organization (pp. 15-36). Cambridge: Cambridge University Press. 
55. Ekman, P. (1999). Basic emotions. In T. Dalgleish \& M. Power (Eds.), Handbook of Cognition and Emotion (pp. 45-60). Sussex, UK: John Wiley \& Sons.

56. Colombetti, G. (2009). From affect programs to dynamical discrete emotions. Philosophical Psychology, $22,407-425$.

57. Panksepp, J. (2011). The basic emotional circuits of mammalian brains: Do animals have affective lives? Neuroscience and Biobehavioral Reviews, 35, 1791-1804.

58. Weisfeld, G.E., \& Goetz, S.M.M. (2013). Applying evolutionary thinking to the study of emotion. Behavioral Sciences, 3, 388-407.

59. Garcia, J., Hankins, W.G., \& Rusiniak, K.W. (1974). Behavioral regulation of the milieu interne in man and rat. Science, 185, 824-831.

60. Anholt, R.R.H. (1994). Signal integration in the nervous system: adenylate cyclises as molecular coincidence detectors. Trends in Neuroscience, 17, 37-41.

61. Volkow, N.D., Wang, G.-J., \& Baler, R.D. (2011). Reward, dopamine and the control of food intake: implications for obesity. Trends in Cognitive Sciences, 15, 37-46.

62. Guillery, R.W., \& Sherman, S.M. (2011). Branched thalamic afferents: What are the messages that they relay to the cortex? Brain Research Reviews, 66, 205-219.

63. Kim, S.W., Schenck, C.H., Grant, J.E., Yoon, G., Dosa, P.I., Odlaug, B.L., Schreiber, L.R.N., Hurwitz, T.D., \& Pfaus, J.G. (2013). Neurobiology of sexual desire. NeuroQuantology, 11, 332-359.

64. Oomura, Y. (1988). Chemical and neuronal control of feeding motivation. Physiology and Behavior, 44, 555-560.

65. Antunes-Rodrigues, J., De Castro, M., Elias, L.L.K., Valenca, M.M., \& McCann, S.M. (2004). Neuroendocrine control of body fluid metabolism. Physiological Reviews, 84, 169-208.

66. Yardley, L., Masson, E., Verschuur, C., Haacke, N., \& Luxon, L. (1992). Symptoms, anxiety and handicap in dizzy patients: Development of the vertigo symptom scale. Journal of Psychosomatic Research, 36, 731741.

67. Beauregard, M., Lévesque, J., \& Bourgouin, P. (2001). Neural correlates of conscious self-regulation of emotion. The Journal of Neuroscience 21, Article Number RC165.

68. Altun, G., Akansu, B., Altun, B.U., Azmak, D., \& Yilmaz, A. (2004). Deaths due to hunger strike: post-mortem findings. Forensic Science International, 146, 35-38.

69. Cookson, L.J. (2013). A desire for parsimony. Behavioral Sciences, 3, 576-586.

70. Cookson, L.J. (1999). Our Wild Niche. San Jose: iUnivserse.

71. Cookson, L.J. (2004). Wildness, the forgotten partner of evolution. Gatherings, J. of the Internat. Community for Ecopsychology, 6 pp.

72. Preti, A. (2007). Suicide among animals: A review of evidence. Psychological Reports, 101, 831-848.

73. Kokkevi, A., Rotsika, V., Arapaki, A., \& Richardson, C. (2012). Adolescents' self-reported suicide attempts, self-harm thoughts and their correlates across 17 European countries. Journal of Child Psychology and Psychiatry, 53, 381-389.

74. Fehr, E., Bernhard, H., \& Rockenbach, B. (2008). Egalitarianism in young children. Nature, 454, 10791084.

75. Hauser, M.D. (2006). Moral Minds: How Nature Designed Our Universal Sense of Right and Wrong. New York: Ecco Press.

76. Bloom, P. (2010). How do morals change? Nature, 464, 490.

77. Bloom, P. (2013). Just Babies: The Origins of Good and Evil. New York: The Crown Publishing Group.

78. Henrich, J., Boyd, R., Bowles, S., Camerer, C., Fehr, E., Gintis, H., \& McElreath, R. (2001). In search of Homo economicus: Behavioral experiments in 15 small-scale societies. The American Economic Review, 91, 7378.

79. Brosnan, S.F., \& de Waal, F.B.M. (2003). Monkeys reject unequal pay. Nature, 425, 297-299. 
80. Singer, T., Seymour, B., O’Doherty, J.P., Stephan, K.E., Dolan, R.J., \& Frith, C.D. (2006). Empathic neural responses are modulated by the perceived fairness of others. Nature, 439, 466-469.

81. Oatley, K., \& Johnson-Laird, P.N. (2011). Basic emotions in social relationships, reasoning, and psychological illnesses. Emotion Review, 3, 424-433.

82. Damasio, A.R., Everitt, B.J., \& Bishop, D. (1996). The somatic marker hypothesis and the possible functions of the prefrontal cortex. Philosophical Transactions of the Royal Society London B, 351, 1413-1420.

83. Bechara, A. (2004). The role of emotion in decision-making: Evidence from neurological patients with orbitofrontal damage. Brain and Cognition, 55, 30-40.

84. Rainville, P. (2002). Brain mechanisms of pain affect and pain modulation. Current Opinion in Neurobiology, 12, 195-204.

85. Wiech, K., Ploner, M., \& Tracey, I. (2008). Neurocognitive aspects of pain perception. Trends in Cognitive Science, 12, 306-313.

86. Kuppens, P., \& Van Mechelen, I. (2007). Interactional appraisal models for the anger appraisals of threatened self-esteem, other-blame, and frustration. Cognition and Emotion, 21, 56-77.

87. Javela, J.J., Mercadillo, R.E., \& Ramirez, J.M. (2008). Anger and associated experiences of sadness, fear, valence, arousal, and dominance evoked by visual scenes. Psychological Reports, 103, 663-681.

88. Harlow, H.F., \& Stagner, R. (1933). Psychology of feelings and emotions. II. Theory of emotions. Psychological Review, 40, 184-195.

89. Price, J.L., \& Drevets, W.C. (2010). Neurocircuitry of mood disorders. Neuropsychopharmacology Reviews, 35, 192-216.

90. Barrett, L.F. (2012). Emotions are real. Emotion, 12, 413-429.

91. Blackhart, G.C., Nelson, B.C., Knowles, M.L., \& Baumeister, R.F. (2009). Rejection elicits emotional reactions but neither causes immediate distress nor lowers self-esteem: A meta-analytic review of 192 studies on social exclusion. Personality and Social Psychology Review, 13, 269-309.

92. Williams, K.D. (2007). Ostracism. Annual Review of Psychology, 58, 425-452.

93. Turner, R.J., Russell, D., Glover, R., \& Hutto, P. (2007). The social antecedents of anger proneness in young adulthood. Journal of Health and Social Behavior, 48, 68-83.

94. Leff, J.P. (1973). Culture and the differentiation of emotional states. British Journal of Psychiatry, 123, 299-306.

95. Heelas, P. (1981). Indigenous representations of emotions: The Chewong. In Indigenous Psychologies: The Anthropology of the Self. San Diego: Academic Press, pp. 87-203.

96. Russell, J.A. (1991). Culture and the categorization of emotions. Psychological Bulletin, 110, 426-450. 